\section{Games without frontiers}

For those promoting peace, the world of videogames might seem one to give as wide a berth as possible.

More often than not encouraging players to indulge in fast paced, point scoring action and see the world from one perspective only, videogames have a seemingly deserved reputation for fostering a war mongering and violent mind set in the young people who find them so compelling. Certainly, this entertainment medium seems inherently at odds with the world of conflict resolution-where the slower the pace, the greater the ability to see the world through others' eyes, and the more focused on the long term, the more likely a "win" is to be achieved.

Those working in the highly charged Middle East region in particular might have good reason to question what videogame technology can offer. After all, not so long ago a videogame from Hezbollah, Special Force, featuring simulated attacks on the
Israeli army, was the top must-have game for the youngsters of Beirut's Shiite neighbourhoods.

As for what has been available to the "other side," America dominates the videogame market and a rash of anti-Arab ones in particular have been released since " $9 / 11$."

ImpactGames's Asi Burak and Eric Brown, however, are hoping to market a game with a difference-a simulation game tackling the Israeli-Palestinian conflict in a progressive way. Their creation, PeaceMaker (www.peacemakergame.com), asks players to first assume either the role of the Israel prime minister or the Palestinian president. They must then interact in their virtual world with eight other "actors"-political leaders and social groups - as well as react to events such as peace negotiations, military attacks, and suicide bombs. The aim is to reach a stable resolution by the end of their prime ministerial or presidential term of office.

The game has three levels of difficultycalm, tense, or violent-though a provocative incident confronts players from the start of the game whichever level is chosen.
Onscreen action takes place using a high resolution map of Israel, the West Bank, and the Gaza strip, and the use of a library of video footage of news events makes it a more real experience for players.

Burak and Brown claim that PeaceMaker allows "what if" scenarios to be explored and events to be seen from alternative perspectives. It also opens the door to further debate, they say.

The game started life as a student project at Carnegie Mellon University's Entertainment Technology Center but the international support it has received has seen it developed into a commercial project.

Brown says: "In a sense, peacemaking can be more complicated, sophisticated, and rewarding than war making. We tried to shed light on how challenging it is for a leader to gain trust and understanding in the face of constant violence. How difficult it is to execute concessions, while your own population is under stress or feeling despair."

Naomi Marks freelance journalist, London naomi@naomimarks.co.uk

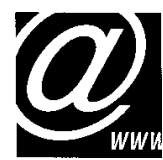

\section{Net gain for Arab health?}

The internet remains a relatively new development within much of the Arab world. Although access and use are rapidly increasing, particularly amongst the young, it still figures relatively little in the day to day life of most Arabs. Where used, it is primarily for social reasons. Very few are likely to log on for health information and advice.

Given this background, the recent launch of Sehetna (www.sehetna.com), Jordan's first Arabic health portal, is therefore somewhat surprising. Also unusual for a health portal in a Muslim country, is the provision of information about sensitive areas such as reproductive health care, family planning, sexually transmitted infections, and HIV/AIDS.

The portal, which was launched earlier this year with the enthusiastic support of King Abdullah II, has been developed by the Jordan Communication Partnership for

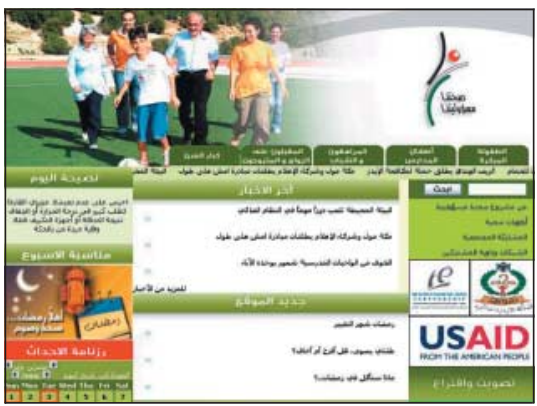

Health advice goes online in Jordan

Family Health Program at Johns Hopkins University Bloomberg School of Public Health, along with government partners.

In addition to simple factual information, there are also daily health tips, online surveys, and physician directories. There is also the opportunity to submit questions through an "Ask the Expert" feature.

However, Arab members of the public who tested the site on our request made comments such as "primitive, uninteresting, and irrelevant." Despite winning this year's Golden Trophy Award (in the health and services category) at the second Pan Arab Web Award, the portal obviously has some way to go to meet public aspirations and override the strong culture of seeking health care from a trusted professional.
The site has a number of other limitations, including difficulties actually finding it through Arab search engines. Many pages are still under construction. There was also a lack of response from the "Ask the Expert" site. We only received an automated holding response a week after lodging a straightforward enquiry about the role of allergen avoidance measures in asthma. Three weeks later, we are still to receive a response.

How then could the site be rendered more useful? First, the portal needs to embrace web-casting, and develop audiovisual materials involving well known artists, sports personalities, and politicians to promote the site. Second, there needs to be far more interactivity-for example, diseasebased discussion forums.

There remains a pressing need for a high quality portal of information for Arab healthcare professionals, but given the limitations of the current site, this is probably beyond the scope of Sehetna.

\section{Yasser Shehata clinical research fellow}

Aziz Sheikh professor of primary care research and development, Division of Community Health Sciences: GP Section, University of Edinburgh, Edinburgh EH8 9DX

Aziz.Sheikh@ed.ac.uk 


\section{Keeping alive the "jazba"}

$\mathrm{T}$

he October 2005 earthquake in northern Pakistan traumatised the nation. More than 73000 people were killed and 3.5 million rendered homeless. As part of the global response to the disaster, many Western mental health professionals of Pakistani origin offered help. Many had left the country years ago, but the earthquake made them return, albeit only for a short time.

What moved them? The emotional bond or guilt for abandoning their parent country? One psychiatrist from the US explained "this was our Katrina [US hurricane] and we had to do something." Whatever it was, there was an incredible "jazba" (spirit) and a desire to help. Many professionals worked in the makeshift camps which housed the survivors, others with children in tented schools. But what now?

Most of the acute psychological reactions of the disaster have subsided but their legacy is set to be large. Pre-earthquake prevalence rates of common mental disorders were already very high and Pakistani mental health resources have long been hopelessly overstretched. In a total health budget of less than $1 \%$ of GDP, mental health does not even have a separate allowance. Despite the fact that more than 35 million people in the country are estimated to suffer from mental disorders, psychiatry is still not taught or examined in most medical schools. It is ironic that where the need is greatest the awareness among professionals is lowest.

The mental health problems of the masses in areas not directly affected by the

\section{large}

Most of the acute psychological reactions of the disaster have subsided but their legacy is set to be

\section{earthquake
that are r
deserve the
enthusiasm
re acute
of the
ave
but their
et to be} imentary at best. These people same commitment, zeal, and mental health professionals, as was shown for the earthquake survivors.

Pakistan is at a crossroads and one of its many challenges is to build sustainable mental health programmes based on patient need and a clearer recognition of the factors which contribute to the high prevalence rates. These include social deprivation, lack of basic needs, denial of justice, abject poverty, and the severely compromised position of women. Underlying issues include poor governance, corruption, and mismanagement. We need to look beyond the

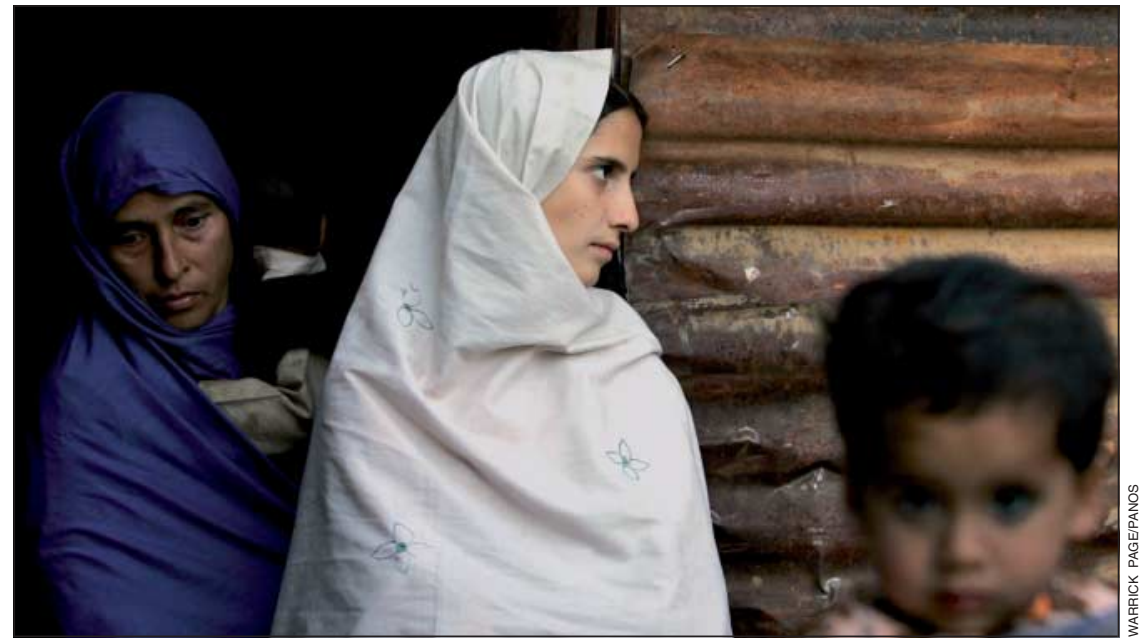

The need for psychiatric services in Pakistan is greater than ever psychological trauma of disaster and programmes such as those set up for posttraumatic stress disorders and establish comprehensive integrated mental health programmes linked with primary care services.

The October 2005 earthquake has given Pakistani psychiatry an extraordinary opportunity to redeem and redefine itself. Public and government awareness of mental health is at a high level and there is an inflow of resources to the country. Mental health professionals must seize this opportunity and push for a comprehensive national mental health programme.

Pakistani psychiatrists in the West are in a unique position to help foster change. Their response following the earthquake has shown their emotional bond to their parent country. Yet their independence from it gives them a strong voice which needs to be used to influence and inform policy and promote high standards. Their experience of working in better organised and resourced health systems in the West is a valuable transferable skill. It needs to be utilised in building capacity in teaching, training, service provision, and research. This requires close interaction and ongoing dialogue with mental health professionals in Pakistan. The "jazba" shown by Pakistani psychiatrists in the West must be kept alive, harnessed and used in the most productive way.

Murad M Khan professor, Department of Psychiatry, Aga Khan University, Karachi

We welcome submissions for the personal view section. These should be no more than 850 words and should be sent electronically via our website. For information on how to submit a personal view online, see http://bmj.com/cgi/content/full/325/ 7360/DC1/1 


\section{Soldiering on}

$\mathrm{L}$ ke you, I have many personal views. But personal views are set aside during working hours, which comprise most waking hours. These views are reserved for my family and friends, around the kitchen table or in the living room. They have no place in the hospital.

In the department where I work personal views are irrelevant. The patients, with acute leukaemia, myeloma, lymphoma, ITP or TTP are fighting for their lives. The fight outside is beside the point. About two thirds are Jews, some native born Israelis, some refugees from Arab countries, some Holocaust survivors, and some survivors of Stalin's reign. Right now five of our inpatients are Arabs (three Palestinians from the West Bank, and two Israeli Arabs from the north of Israel). All of them felled by platelets too low or too high, white cells too immature or lymph nodes too large. Who knows

if they are rooting for Olmert or Nasrallah, Hamas or Abbas? We are all rooting for the neutrophils to go up, the fever to go down, the platelet count to normalise.

I'd like to be able to say that all of our judgments are purely medical, but occasionally we do have to debate issues of insurance coverage, drug availability, or whether to send a patient with a borderline neutrophil count home. Perhaps he will be delayed at a checkpoint and arrive septic, or even worse, not arrive. When I lived in Canada we had similar considerations, although the issue there was snow. There we were reluctant to release a leukopenic patient for fear his/her return might be delayed by a blizzard. Climates can be political, economic or meteorological but in all cases they may affect clinical decision making.

Five years ago, personal views were set aside when we came in to make rounds at

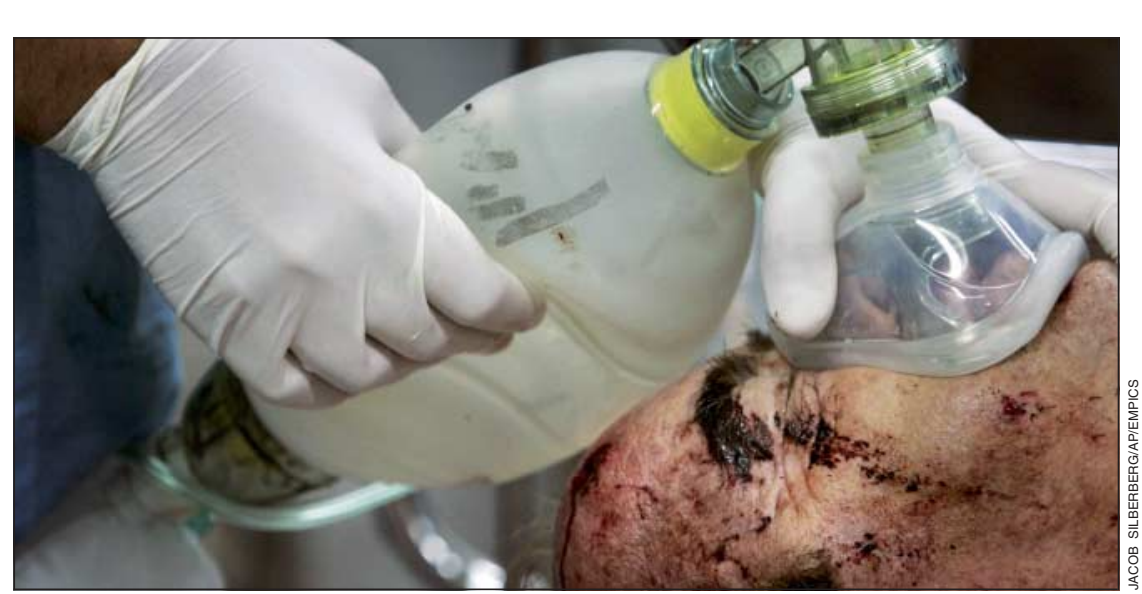

A casualty in north Israel
6 am on our patients the morning of the funeral of our colleague Dr Shmuel Gillis, originally of Sunderland. He had been shot to death the previous evening on his way home from the hospital. Although the hour was late and his daughter was celebrating her bat mizvah (12th birthday) he had run to see a Palestinian patient who, after years of infertility, had delivered a child thanks to his care. At 9 am, after examining all the patients and making sure they were safe, hear the eulogies. Coworkers, family, friends, and patients wept in despair, Jews and Arabs alike. Although half a decade has passed, none of us has quite recovered from this loss, not the least my colleague from Beit Jalla (a Palestinian town across the valley), Shmuel's friend.

I have lived in Israel for 14 years. During this time the region has seen peace treaties, political assassinations, intifadas, troop withdrawals and, as I write these words, a war. I can honestly say that patient care has never been compromised by these cataclysmic events. In the past few weeks both Jewish and Arab patients from the north of the country have been difficult to discharge. Arab and Jewish towns alike have been barraged by Katyusha rockets, making our hospital in Jerusalem a safe refuge, despite the food, the MRSA and ESBL.

My own personal view is that we should be allowed to live in peace- but it seems that other people view things differently. But there is really no time for personal views. People are sick and need to be looked after.

Ora Paltiel associate professor, School of Public Health and Department of Haematology, Hadassah-Hebrew University Hospital,Jerusalem, Israel

ora@vms.huji.ac.il we went out to the hospital parking lot to

\section{SOUNDINGS}

\section{All Russian to me}

My wife is learning Russian, apparently for fun. Subjunctives in Cyrillic, she says, are light relief from the bureaucracy of general practice. Our house is filling up with the works of Pushkin and books about Russian history. Vaguely interested, I found the country's troubled past hard to understand until I noticed the parallels with the NHS.

For example, two centuries ago the czar and the ruling class spoke French whereas the serfs spoke Russian. How on earth could two groups who had to coexist speak different languages? Then I remembered the NHS's managerial memos with nouns like "stakeholder," verbs like "drill down," and all those trendy abbreviations. Staff involved in patient care don't talk like that and have silent, serf-like contempt for those who do.

Then, during the communist era, Soviet policy was decreed by a leader in Moscow and applied, blanket fashion, across the country. Small town apparatchiks knew that disobedience meant death. Today, NHS middle managers believe their jobs (not their lives, admittedly) are on the line if they fail to implement the schemes of Downing Street advisers. Decisions come from large buildings in Leeds and London but are rarely announced. Instead, all trusts miraculously have the same cost cutting ideas at the same time. Only when the serfs go networking, perhaps at meetings of the Royal College of Serfs, do they realise what is happening.

When public announcements are made, they take the form of what used to be called "propaganda" and is now "spin". The Russian people would be told that the state was making more combine harvesters than ever before, and the books would be cooked to prove that nobody had to wait more than six weeks for a tractor. How nice it would be if the NHS, besides using similar techniques, went the whole hog and produced totalitarian artwork. Staff would be inspired by posters of square jawed doctors and nurses looking upwards, fists upraised, with guidelines unfurling behind them.

And finally, when the Soviet Union fell, the oligarchs took over. Young men became fabulously rich in mysterious ways and bought foreign football clubs. We serfs suspect that some people are doing very nicely out of the NHS. And if we find our premiership team playing PFI Moscow, our suspicions will deepen.

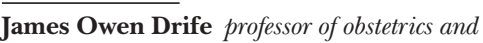
gynaecology, Leeds 